\title{
Application of Mercury Temperature Programmed Desorption (HgTPD) to ascertain mercury/char interactions
}

M. Rumayor, N. Fernandez-Miranda, M. A. Lopez-Anton*, M. Diaz-Somoano, M. R. Martinez-Tarazona

Instituto Nacional del Carbón (CSIC), C/Francisco Pintado Fe, 26, 33011, Oviedo, Spain

*Corresponding autor: M. Antonia Lopez-Anton

Phone: +(34) 985119090

Fax: $\quad+(34) 985297662$

e-mail: marian@incar.csic.es 


\begin{abstract}
This work investigates the scope of a Mercury Temperature Programmed Desorption (HgTPD) technique for identifying mercury species in solids. The specific objective of this study was to clarify the mechanism of mercury retention by chars used as sorbents in coal combustion in air and oxy-combustion atmospheres based on the identification of the mercury species retained. Different mercury species were identified by HgTPD depending on the flue gas composition and the type of char. The results lead to the conclusion that depending on these conditions the main mechanism of mercury retention will be the interaction of mercury with organic matter, or the interaction of mercury with sulfur to form $\mathrm{HgS}$. In a few particular cases $\mathrm{Hg}_{2}\left(\mathrm{NO}_{3}\right)_{2} 2 \mathrm{H}_{2} \mathrm{O}$ was produced on the char surface. It was found that HgTPD is a highly useful technique for investigating the different mechanisms of mercury/char/gas interactions.
\end{abstract}

Keywords: mercury; chars; biomass; gasification; combustion 


\section{Introduction}

The high toxicity of mercury and the effects of this element on human health are well known problems [1]. Likewise, it is generally acknowledged that coal-fired power plants are one of the largest anthropogenic sources of mercury emissions to the environment [2]. As an example, in Spain 1 ton/year of mercury was emitted from coal combustion plants in 2012 . This represents $40 \%$ of the total amount of mercury emitted in this country [3], with coal contributing nearly $20 \%$ to the energy supply in this year. The seriousness of this problem has led governments to establish standards of mercury emissions [4-6], and has encouraged the scientific community to develop cost-effective technologies to reduce these emissions.

The most commonly used method for mercury retention in conventional coal combustion is the injection of activated carbons (ACs) in the flue gas [7]. The efficiency of this technology depends on the speciation of the mercury. Mercury in combustion flue gases may be bound to particulate matter $\left(\mathrm{Hg}_{\mathrm{p}}\right)$, which is mainly retained in particle control devices, or it may remain in the vapor state as oxidized $\left(\mathrm{Hg}^{2+}\right)$ or as elemental $\left(\mathrm{Hg}^{0}\right)$ [8-9]. Although the proportion of these species will depend, among other factors, on the combustion flue gas composition, mercury speciation in conventional coal combustion in air is relatively well known compared to oxy-combustion where the behavior of mercury still requires considerable research. Oxy-combustion is one of the promising emerging technologies for performing coal combustion with $\mathrm{CO}_{2}$ capture. The basic concept of oxy-combustion is to replace combustion in air by combustion in a mixture of oxygen and recycled flue gas and/or water for temperature control. In this way, the remaining flue gas, rich in $\mathrm{CO}_{2}$ and water vapor, can be easily separated to yield a stream of $\mathrm{CO}_{2}$ ready for utilization or sequestration. Oxy-combustion implies, 
therefore, a reduction in $\mathrm{CO}_{2}$ emissions from coal-fired power plants which is a necessary pre-requisite for controlling and limiting global warming.

Although ACs are well-proven sorbents with a mercury removal efficiency of up to $90 \%$, further advances are still necessary in AC technology to reduce costs and to limit the balance-of-plant impacts associated with its use [7,10]. In their search for highquality and low-cost alternatives some researchers have focused on the use of industrial or agricultural wastes as sorbents for mercury or as precursors for obtaining mercury sorbents [11-14]. Previous studies carried out by the present authors [15-16] have demonstrated that some chars obtained from gasification of biomass particularly from paper and plastic wastes, show similar mercury retention capacities to that of Filtracarb $\mathrm{D} 47 / 7+\mathrm{S}$, a commercial activated carbon especially designed for the capture of $\mathrm{Hg}^{0}$. The main advantage of using these chars, apart from the revalorization of an industrial waste, is that the chars do not have to be pretreated or impregnated, which in itself implies a reduction in costs. Char sorbents were therefore used in this study in oxycombustion conditions and compared with previous results obtained in conventional air combustion atmospheres. Mercury behavior in oxy-coal combustion is of major concern because not only does it cause serious environmental problems but it can also damage the aluminum components of the $\mathrm{CO}_{2}$ compression units. Although several coal chars and biomass chars have already been tested in a variety of conditions for mercury adsorption [14,17-20], and has been shown that the surface functionality of chars and chlorine and sulfur species play an important role in mercury retention, no mechanism for mercury adsorption has been clearly established. In this study an attempt is made to explain mercury/char interactions in gases produced in different coal combustion systems. To achieve this goal, identification of the mercury species present on solids is a necessary prerequisite. 
Despite the enormous usefulness of analytical techniques able to identify the mode of occurrence of low concentrations of mercury species in solids, the progress made so far has not been very satisfactory. Techniques such as X-ray absorption finestructure spectroscopy (EXAFS) [21, 22] and X-ray absorption near edgestructure (XANES) [23], are able to produce a characteristic spectra for each mercury compound. However, these techniques often present interference; the data processing is complex and the detection limits (100 ppm) are not usually appropriate for the analysis of the majority of the solid samples. Another technique is sequential chemical extraction (SCE) [24-27] which is based on the different solubilities of mercury compounds. The main drawbacks of this method are its low selectivity because the complete extraction of each fraction depends on the time; not all mercury species can be distinguished and it is a tedious method with many sources of uncertainty. In this work the identification of mercury species in the char samples used for mercury capture is carried out by means of a thermal desorption procedure (HgTPD). This technique of identifying mercury species is based on the temperature at which they are released [28-31]. The method has proven to be a relatively simple and selective procedure for the identification of mercury species in concentrations lower than $10 \mathrm{ppm}$. The identification of mercury species can be expected to play a key role in the development of the most appropriate solid sorbent for each particular case.

\section{Experimental}

Two previously characterized chars [15] were employed as mercury sorbents for this study. The chars were by-products of the gasification of wood wastes (WW) and a mixture of paper and plastic wastes $(\mathrm{PW})$. They were tested under a simulated flue gas 
of coal combustion and oxy-combustion and then subjected to thermal desorption (HgTPD) for the purpose of identifying their mercury species.

The experimental device used to retain the mercury consisted of i) a glass reactor containing the sorbent bed $(50 \mathrm{mg}$ of char $(40-60 \mu \mathrm{m})$ mixed with $650 \mathrm{mg}$ of sand (200$300 \mu \mathrm{m})$ ), ii) a permeation tube for the generation of elemental mercury in gas phase, the mercury concentration in gas phase being $100 \mu \mathrm{g} \mathrm{m}^{-3}$ iii) a gas blending station in which the two atmospheres were prepared (Table 1) and iv) a continuous mercury analyzer (VM-3000) that monitored the $\mathrm{Hg}^{0}$. The $\mathrm{Hg}^{2+}$ was captured by an ion exchanger resin (Dowex 1x8), suitable for the selective extraction of $\mathrm{Hg}^{2+}$ species [32]. The resin was conditioned with a solution of $\mathrm{HCl}: \mathrm{H}_{2} \mathrm{O}(1: 1)$ at $90^{\circ} \mathrm{C}$ for 30 minutes and then filtered and dried. The resin was placed prior to the $\mathrm{Hg}^{0}$ continuous analyzer in such a way that the total mercury concentration was balanced. The $\mathrm{Hg}^{2+}$ in the resin at the end of the experiments and the mercury retained in the sorbent were determined by means of an automatic mercury analyzer (AMA 254). The temperature of the sorbent was kept at $150{ }^{\circ} \mathrm{C}$ and the flow rate through the sorbent was $0.5 \mathrm{~L} \mathrm{~min}^{-1}$. The duration of the mercury experiments was the time needed for the samples to reach maximum retention capacity, i.e. the maximum amount of mercury that a sorbent can retain until it reaches its point of saturation, expressed as micrograms of mercury per $g$ of sorbent. Maximum retention capacity is represented by the mercury adsorption curves obtained using a continuous VM-3000 analyzer.

The experimental device employed to identify the mercury species in the postretention chars consisted of an advanced RA-915 Mercury analyzer coupled to a PYRO915 furnace (Ohio Lumex). $20 \mathrm{mg}$ of sample was introduced in the first chamber of the PYRO-915. Inside this chamber the mercury compounds were released from the solid matrix under a controlled heating mode. The parameters for the selective desorption of 
the mercury had previously been optimized by the authors [31]. A four-step program was set up. The temperature rate was kept at $40{ }^{\circ} \mathrm{C} \min ^{-1}$ for $575 \mathrm{~s}$. Then the heating velocity was increased up to $50{ }^{\circ} \mathrm{C} \mathrm{min}^{-1}$ where it was held for $200 \mathrm{~s}$ and then again up to $80{ }^{\circ} \mathrm{C} \mathrm{min}-1$ where it was held for a further $125 \mathrm{~s}$. Air was used as carrier gas at $1 \mathrm{~L} \mathrm{~min}^{-}$ ${ }^{1}$. In the second chamber of the PYRO-915 kept at a temperature of $800^{\circ} \mathrm{C}$, the desorbed mercury compounds were reduced to elemental mercury which was detected by atomic absorption spectrometry. The mercury species were identified from the temperature range in which they were released. This range comprises the temperature at which thermal release starts, reaches its maximum point and then returns to the baseline. The desorption profiles of the samples were compared with the reference desorption profiles of fifteen pure mercury compounds obtained in a previous work [31]. Two new mercury compounds were added to this reference database: $\mathrm{HgS}$ black and $\mathrm{Hg}-\mathrm{OM}$ (mercury bound to organic matter). The $\mathrm{Hg}-\mathrm{OM}$ species had not been considered in a previous desorption study with char samples [20]. The mercury standard for organic matter was prepared from a humic acid [33]. The humic acids contain $\mathrm{COOH}, \mathrm{OH}$ and $\mathrm{CO}$ groups and, although the evolution of these groups depends on the rank of coal, this mercury compound was chosen as being representative of organic groups in coals [34-35].

The results obtained by HgTPD were compared with those obtained by the method based on sequential extraction. The procedure previously described [36] is a simplification of the US Environmental Protection Agency Method 3200 (US EPA Method 3200), which consists of three sequential extraction steps that split mercury species into three fractions depending on the solubility of each species in each fraction: F1 (mobile $\mathrm{Hg}$ (inorganic and organic $\mathrm{Hg}$ )), F2 (semi-mobile $\mathrm{Hg}$ (mainly $\mathrm{Hg}^{0}, \mathrm{Hg}^{2+}$ complexes) and F3 (non-mobile $\mathrm{Hg}$ (mainly $\mathrm{HgS}$ ). 


\section{Results and discussion}

The mercury retention capacities and the mercury adsorption curves for the two chars obtained from the gasification of wood waste (WW) and plastic plus paper waste (PW), under combustion and oxy-combustion atmospheres (Table 1), are presented in Table 2 and Figure 1. The PW char has a higher mercury retention capacity than WW in both atmospheres, as was observed in the previous studies [15-16]. The previous studies were performed in air combustion atmospheres containing the following reactive gases: $\mathrm{O}_{2}, \mathrm{SO}_{2}, \mathrm{NO}_{2}, \mathrm{HCl}$, balanced with $\mathrm{N}_{2}$. From the effect of the characteristics of the chars on mercury retention it was concluded that the higher retention capacity of the PW chars was mainly due to their higher chlorine content (5\%) and/or aluminum content $(7 \%)$, i.e, elements with which mercury may react or amalgamate. It should be noted that the mercury retention capacities shown in Table 2 are the result of analyzing the sorbent directly by means of the AMA equipment. They represent the total amount of mercury retained in the sorbent $\left(\mathrm{Hg}^{0}+\mathrm{Hg}^{2+}\right)$. The kinetics of adsorption are reflected in the mercury adsorption curves (Figure 1). The PW chars slowly start to adsorb mercury reaching their maximum retention capacity after approximately 500 minutes, whereas the WW chars quickly reach their maximum retention capacity. The oxidation of $\mathrm{Hg}^{0}$ may also be occurring in both chars. It must be remembered that the VM analyzer only detects $\mathrm{Hg}^{0}$.

Figure 2 shows the percentages of i) mercury retained in the chars (i.e., Hgp), ii) the oxidized mercury in gas phase $\left(\mathrm{Hg}^{2+}\right)$, resulting from homogeneous oxidation (gas-gas interaction) plus heterogeneous oxidation (gas-char interaction), and iii) the elemental mercury that was not retained in the sorbent $\left(\mathrm{Hg}^{0}\right)$. $\mathrm{The}_{\mathrm{Hg}}^{2+}$ at the outlet of the reactor was determined by capturing it in an ion exchanger resin suitable for the selective extraction of $\mathrm{Hg}^{2+}$ species [32]. A resin bed was placed after the reactor for each 
mercury experiment which was then analyzed by means of the AMA equipment. $\mathrm{Hg}^{2+}$ from homogeneous oxidation is the result of an analysis of the resin without the sorbent whereas the $\mathrm{Hg}^{2+}$ from heterogeneous oxidation is the $\mathrm{Hg}^{2+}$ retained in the resin after the reactor with the sorbent. $30 \%$ of the $\mathrm{Hg}^{2+}$ was originated by homogeneous oxidation, as established in a previous study using the same oxy-combustion and combustion with air atmospheres [37]. In the present study, similar mercury retention capacities and mercury species distributions were obtained with the char from the gasification of wood waste (WW) in both atmospheres. However, in the case of the char obtained from the gasification of plastic and paper waste (PW) not only was a higher mercury capture achieved under oxy-combustion conditions but also a higher heterogeneous mercury oxidation $(30 \%)$. As can be seen in Figure 1, whereas WW shows similar mercury adsorption curves for both atmospheres, PW shows a different kinetic behaviour, indicating that the gas composition plays a role in the retention mechanism. These results suggest that different mercury species are retained or formed in the PW chars due to interactions with the gases in the atmosphere. It is therefore essential to be able to identify the mercury species in the sorbents in order to understand the mechanism of adsorption of mercury.

Mercury compounds were identified in the post-retention chars using the thermal desorption procedure (HgTPD) optimized by the authors in a previous study [31]. For this purpose, the desorption profiles of the mercury species present in the chars were compared with the desorption profiles of the mercury reference compounds (Figures 34). Table 3 summarizes the high peak temperatures of the reference compounds likely to be found in post-retention chars. Similar mercury desorption curves were obtained for WW in the atmospheres of coal combustion (WW-CO) and oxy-combustion (WW-OX), the area below the curve being slightly lower in WW-CO due to the lower mercury 
retention. The mercury species retained in these atmospheres can be expected to be the same. The main mercury species identified were $\mathrm{Hg}-\mathrm{OM}$ and $\mathrm{Hg}_{2}\left(\mathrm{NO}_{3}\right)_{2} 2 \mathrm{H}_{2} \mathrm{O}$ (Figure 3) in both atmospheres. Where there is a large amount of organic matter, mercury can be expected to be bound to it. In fact, the loss of ignition (LOI) values which is an estimation of carbon content are 55\% and 51\% for PW and WW chars, respectively [15]. The formation of $\mathrm{Hg}_{2}\left(\mathrm{NO}_{3}\right)_{2} 2 \mathrm{H}_{2} \mathrm{O}$ can be explained by the fact that the gas compositions contain a relatively high concentration of NOx (Table 1). Reactions between the NOx species and the $\mathrm{Hg}^{0}$ in gas phase may give rise to different mercury nitrates that might condense on the surface of the char sorbents. The formation of the different mercury nitrates could then occur via the following reactions [16]:

$$
\begin{aligned}
& 4 \mathrm{Hg}^{0}(\mathrm{~g})+6 \mathrm{NO}_{2}(\mathrm{~g}) \rightarrow \mathrm{Hg}_{2}\left(\mathrm{NO}_{3}\right)_{2}+\mathrm{Hg}_{2}\left(\mathrm{NO}_{2}\right)_{2}+2 \mathrm{NO}(\mathrm{g}) \\
& 4 \mathrm{Hg}^{0}(\mathrm{~g})+4 \mathrm{NO}_{2}(\mathrm{~g})+\mathrm{O}_{2}(\mathrm{~g}) \rightarrow \mathrm{Hg}_{2}\left(\mathrm{NO}_{3}\right)_{2}+\mathrm{Hg}_{2}\left(\mathrm{NO}_{2}\right)_{2} \\
& 4 \mathrm{Hg}^{0}(\mathrm{~g})+6 \mathrm{NO}(\mathrm{g})+3 \mathrm{O}_{2}(\mathrm{~g}) \rightarrow \mathrm{Hg}_{2}\left(\mathrm{NO}_{3}\right)_{2}+\mathrm{Hg}_{2}\left(\mathrm{NO}_{2}\right)_{2}+2 \mathrm{NO}(\mathrm{g}) \\
& 4 \mathrm{Hg}^{0}(\mathrm{~g})+4 \mathrm{NO}(\mathrm{g})+3 \mathrm{O}_{2}(\mathrm{~g}) \rightarrow \mathrm{Hg}_{2}\left(\mathrm{NO}_{3}\right)_{2}+\mathrm{Hg}_{2}\left(\mathrm{NO}_{2}\right)_{2}
\end{aligned}
$$

These mercury species, mainly $\mathrm{Hg}_{2}\left(\mathrm{NO}_{3}\right)_{2}$, crystallize from slightly acidified aqueous solutions (the formation of $\mathrm{HNO}_{2}$ (aq) and/or $\mathrm{HNO}_{3}$ (aq) has been confirmed in atmospheres containing $\mathrm{NOx}$ and $\mathrm{H}_{2} \mathrm{O}$ [37]), in the form of dehydrate. When the overlapping peaks are deconvoluted, the desorption curve for WW shows a shoulder at $150^{\circ} \mathrm{C}$ and another between $250-370^{\circ} \mathrm{C}$ a little higher than the peak corresponding to $\mathrm{Hg}_{2}\left(\mathrm{NO}_{3}\right)_{2} 2 \mathrm{H}_{2} \mathrm{O}$ (Figure 3). The maximum temperature of decomposition for $\mathrm{HgCl}_{2}$ and $\mathrm{HgS}$ red is approximately at 140 and $300^{\circ} \mathrm{C}$, respectively [31] and so the possible formation of these species cannot be ruled out. In addition to these species, it needs to 
be taken into consideration that $\mathrm{HgS}$ black decomposes at $190^{\circ} \mathrm{C}$ and may overlap with the curve corresponding to $\mathrm{Hg}-\mathrm{OM}\left(220^{\circ} \mathrm{C}\right)$ (Table 3$)$.

In order to verify the mercury species identified in the chars, a series of extractions were carried out by sequential extraction [36] and then analysed by HgTPD (Figure 4). The results after the extraction of F1 (inorganic compounds such as mercury nitrates and mercury chlorides) in WW confirm the formation of mercury nitrates and $\mathrm{HgCl}_{2}$, the latter in a low concentration (Figure 4a). As can be seen, the main peaks that remain in the char after the extraction of F1 correspond to Hg-OM and/or HgS (F2-F3). HgTPD analysis of fraction $\mathrm{F} 3$ confirms a) the presence of $\mathrm{HgS}$ red in $\mathrm{WW}$ by the peak at $300^{\circ} \mathrm{C}$ and $\mathrm{b}$ ) that the peak at around $200^{\circ} \mathrm{C}$ corresponds effectively to $\mathrm{Hg}-\mathrm{OM}$ and not to $\mathrm{HgS}$ black since $\mathrm{Hg}-\mathrm{OM}$ was extracted from the semi-mobile fraction F2.

The desorption profiles of PW (Figure 5) show different distributions of mercury species retained in coal combustion with air and oxy-combustion which might explain the differences in mercury retention capacities (Table 2). Whereas $\mathrm{HgS}$ red (peak centered at $300^{\circ} \mathrm{C}$ ) is the main species in coal combustion in air, in the oxy-combustion atmosphere $\mathrm{Hg}-\mathrm{OM}$ is the principal species. As in the case of WW, in $\mathrm{PW}$ the presence of $\mathrm{HgS}$ black and $\mathrm{HgCl}_{2}$ cannot be ruled out. It is important to bear in mind that not only is $\mathrm{HCl}$ present in the gas composition but also that the chars from plastic and paper waste contain a high amount of chlorine [15]. The formation of mercury nitrates might also occur in PW in same way as it does in WW. However, when the mercury retention is as high as in PW the main interactions are between mercury and sulfur and between mercury and organic matter in combustion and oxy-combustion conditions, respectively (Figure 5). 
The results obtained from the HgTPD analysis of the residues after sequential extraction of PW-OX verify the formation of $\mathrm{Hg}-\mathrm{OM}$. After the extraction from $\mathrm{F} 1$ of $\mathrm{HgCl}_{2}$ and mercury nitrates, and from $\mathrm{F} 2$ of $\mathrm{Hg}-\mathrm{OM}$, the only peak remaining is the one corresponding to $\mathrm{HgS}$ red $\left(300^{\circ} \mathrm{C}\right)$ (Figure $\left.4 \mathrm{~b}\right)$. The $\mathrm{HgTPD}$ analysis of the sample after total extraction, (F4), confirms that $\mathrm{HgS}$ red is the other main species present in $\mathrm{PW}$ (Figure $4 \mathrm{~b}$ ) since the peak at $300^{\circ} \mathrm{C}$ has disappeared.

Because in oxy-combustion conditions a high concentration of $\mathrm{H}_{2} \mathrm{O}$ is present, $\mathrm{H}_{2} \mathrm{SO}_{4}$ may form from $\mathrm{SO}_{2} / \mathrm{SO}_{3}$ [37]. Sulfuric acid would favour the adsorption of $\mathrm{Hg}^{0}$ on the surface of the organic matter [38] which would explain the formation of the $\mathrm{Hg}$ $\mathrm{OM}$ species. Moreover, $\mathrm{H}_{2} \mathrm{SO}_{4}$ might favor mercury oxidation on the carbon surface [38] of PW which would accord with the higher heterogeneous oxidation observed in PW under oxy-combustion conditions (Figure 2). This different behavior is not observed in WW. Although both chars have similar LOI contents, the BET surface of WW is lower $\left(2 \mathrm{~m}^{2} \cdot \mathrm{g}^{-1}\right)$ than in PW $\left(65 \mathrm{~m}^{2} \cdot \mathrm{g}^{-1}\right)$ [15], and the interactions between mercury and organic matter are less likely. The predicted concentrations of each species obtained via peak integration using Origin 6.0 software are shown in Figure 6 where a summary of the percentages of each species found in the post-retention chars is presented.

\section{Conclusions}

The chars from the gasification of paper and plastic wastes showed high mercury retention capacities in conditions of conventional coal combustion with air and oxycombustion. In oxy-combustion conditions the chars also demonstrated a high heterogeneous oxidation capacity. 
Different mercury species were identified on the chars by HgTPD technique after they had been used as sorbents depending on the composition of the flue gas and the type of char. This analysis was the key to interpreting the results. In an atmosphere enriched in $\mathrm{CO}_{2}$ and $\mathrm{H}_{2} \mathrm{O}$ the main mechanism of mercury retention in the chars with the highest retention capacity was the interaction with organic matter, while in an atmosphere with less $\mathrm{CO}_{2}$ and $\mathrm{H}_{2} \mathrm{O}$, such as that of conventional coal combustion, $\mathrm{Hg}-\mathrm{S}$ associations were mainly responsible for mercury capture. The principal mercury species identified in the char with the lowest mercury retention capacity (wood waste), was mercury bound to organic matter and $\mathrm{Hg}_{2}\left(\mathrm{NO}_{3}\right)_{2} 2 \mathrm{H}_{2} \mathrm{O}$ in both conditions. With the HgTPD technique it was also possible to identify other minority mercury species such as $\mathrm{HgCl}_{2}$.

\section{Acknowledgments}

The financial support for this work was provided by the National Research Program under project CTM2011-22921. The authors thank the Energy Research Centre of the Netherlands for supplying the chars employed in this study, the Spanish Research Council (CSIC) for awarding Ms. Marta Rumayor a JAE-predoc fellowship and PCTI Asturias for awarding Ms. Nuria Fernandez-Miranda a pre-doctoral fellowship.

\section{References}

[1] T.W. Clarkson, L. Magos, G.J. Myers, The Toxicology of Mercury - Current Exposures and Clinical Manifestations, N. Engl. J. Med. 349 (2003) 1731-1737. 
[2] M. Rallo, M.A. López-Antón, M.L. Contreras, M.M. Maroto-Valer, Mercury policy and regulations for coal-fired power plants, Environ. Sci. Pollut. R. 19 (2012) 10841096.

[3] Spanish Pollutant Release and Transfer Register (PRTR) 2012; http://www.prtres.es/informes/pollutant.aspx

[4] United Nations Environmental Programme. Process Optimization Guidance for Reducing Mercury Emissions from Coal Combustion in Power Plants. 2010; http://www.unep.org/hazardoussubstances/Portals/9/Mercury/Documents/coal/UNE P\%0Mercury\%20POG\%20FINAL\%202010...pdf

[5] Environmental Protection Agency of United States. National Emission Standards for Hazardous Air Pollutants from Coal and Oil-fired Electric Utility Steam Generating Units and Standards of Performance for Fossil-Fuel-Fired Electric Utility, Industrial-Commercial-Institutional, and Small Industrial- Commercial-Institutional $\begin{array}{llll}\text { Steam } & \text { Generating } & \text { Units. }\end{array}$ http://www.epa.gov/mats/pdfs/20111216MATSfinal.pdf

[6] Canadian Council of Ministers of the Environment. Canada-wide Standards for Mercury Emissions from Coal-fired Electric Power Generation Plants. 2006; http://www.ccme.ca/assets/pdf/hg_epg_cws_w_annex.pdf

[7] S. Sjostrom, M. Durham, C.J. Bustard, C. Martin, Activated carbon injection for mercury control: Overview, Fuel 89 (2010) 1320-1322.

[8] K.C. Galbreath, C.J. Zygarlicke, Mercury transformations in coal combustion flue gas, Fuel Process. Technol. 65-66 (2000) 289-310. 
[9] T.K. Gale, B.W. Lani, G.R. Offen, Mechanisms governing the fate of mercury in coal-fired power systems, Fuel Process. Technol. 89 (2008) 139-151.

[10] D.F. Pflughoeft-Hassett, D.J. Hassett, T.D. Buckley, L.V. Heebink, J.H. Pavlish, Activated carbon for mercury control: Implications for fly ash management, Fuel Process. Technol. 90 (2009) 1430-1434.

[11] G. Skodras, I. Diamantopoulou, A. Zabaniotou, G. Stavropoulos, G.P. Sakellaropoulos, Enhanced mercury adsorption in activated carbons from biomass materials and waste tires, Fuel Process. Technol. 88 (2007) 749-758.

[12] Z. Tan, J. Qiu, H. Zeng, H. Liu, J. Xiang, Removal of elemental mercury by bamboo charcoal impregnated with $\mathrm{H}_{2} \mathrm{O}_{2}$, Fuel 90 (2011) 1471-1475.

[13] N. Asasian, T. Kaghazchi, M. Soleimani, Elimination of mercury by adsorption onto activated carbon prepared from the biomass material, J. Ind. Eng. Chem. 18 (2012) 283-289.

[14] K.T. Klasson, I.M. Lima, L.L. Boihem Jr., L.H. Wartelle, Feasibility of mercury removal from simulated flue gas by activated chars made from poultry manures, $\mathrm{J}$. Environ. Manage. 91 (2010) 2466-2470.

[15] A. Fuente-Cuesta, M. Diaz-Somoano, M.A. Lopez-Anton, M. Cieplik, J.L.G. Fierro, M.R. Martinez-Tarazona, Biomass gasification chars for mercury capture from a simulated flue gas of coal combustion, J. Environ. Manage. 98 (2012) 2328.

[16] A. Fuente-Cuesta, M.A. Lopez-Anton, M. Diaz-Somoano, M.R. MartínezTarazona, Retention of mercury by low-cost sorbents: Influence of flue gas composition and fly ash occurrence, Chem. Eng. J. 213 (2012) 16-21. 
[17] M.M. Maroto-Valer, Y. Zhang, B.G. Miller, E. Granite, Z. Tang, H. Pennline, 2004. Mercury oxidation and capture by coal chars. Available in: http://acs.omnibooksonline.com/data/papers/2004_L035.pdf

[18] A.M. Rubel, R. Andrews, R. Gonzalez, J. Groppo, T. Robl, Mercury adsorption on combustion and gasifier by-products. Presented in the 56th Southeast Regional Meeting of the American Chemistry Society, November 10-13, 2004. Research Triangle Park, North Carolina, USA.

[19] B. Wu, T.W. Peterson, F. Shadman, C.L. Senior, J.R. Morency, F.E. Huggins, G.P. Huffman, Interactions between vapour-phase mercury compounds and coal char in synthetic flue gas, Fuel Process. Technol. 63 (2000) 93-107.

[20] M. Rallo, A. Fuente-Cuesta, M.A. López-Antón, M. Díaz-Somoano, M.R. Martínez-Tarazona, M.M. Maroto-Valer, Speciation of Hg retained in gasification biomass chars by temperature-programmed decomposition, Fuel Process. Technol. $126(2014) 1-4$.

[21] C.S. Kim, G.E. Brown, J.J. Rytuba, Characterization and speciation of mercurybearing mine wastes using X-ray absorption spectroscopy (XAS), Sci. Total Environ. 261 (2000) 157-168.

[22] C.S. Kim, J.J. Rytuba, G.E. Brown, EXAFS Study of Mercury(II) Sorption to Feand Al-(hydr)oxides I. Effects of pH, J. Colloid Interface Sci. 271 (2004) 1-15.

[23] C.S. Kim, S. Bloom, J.J. Rytuba, G.E. Brown, Mercury speciation by extended Xray absorption fine structure (EXAFS) spectroscopy and sequential chemical extractions: a comparison of speciation methods, Environ. Sci. Technol. 37 (2003) $5102-5108$. 
[24] R. Fernández-Martínez, M.I. Rucandio, Study of extraction conditions for the quantitative determination of $\mathrm{Hg}$ bound to sulfide in soils from Almaden (Spain), Anal. Bioanal. Chem. 375 (2003) 1089-1096.

[25] N.W. Revis, T.R. Osborne, D. Sedgley, A. King, Quantitative method for determining the concentration of mercury(II) sulphide in soils and sediments, Analyst 114 (1989) 823-825.

[26] H. Sakamoto, T. Tomiyasu, N. Yonehara, Differential determination of organic mercury, mercury(II) oxide and mercury(11) sulfide in sediments by cold vapor atomic absorption spectrometry, Anal. Sci. 8 (1992) 35-39.

[27] R. Rubio, G. Rauret, Validation of the methods for heavy metal speciation in soils and sediments, J. Radioanal. Nucl. Chem. 208 (1996) 529-540.

[28] H. Biester, C. Scholz, Determination of mercury binding forms in contaminated soils: Mercury pyrolysis versus sequential extractions, Environ. Sci. Technol. 31 (1997) 233-239.

[29] M. Rallo, M.A. Lopez-Anton, R. Perry, M.M. Maroto-Valer, Mercury speciation in gypsums produced from flue gas desulfurization by temperature programmed decomposition, Fuel 89 (2010) 2157-2159.

[30] M.A. Lopez-Anton, R. Perry, P. Abad-Valle, M. Diaz-Somoano, M.R. MartinezTarazona, M.M. Maroto-Valer, Speciation of mercury in fly ashes by temperature programmed decomposition, Fuel Process. Technol. 92 (2011) 707-711.

[31] M. Rumayor, M. Diaz-Somoano, M.A. Lopez-Anton, M.R. Martinez-Tarazona, Mercury compounds characterization by thermal desorption, Talanta 114 (2013) 318-322. 
[32] A. Fuente-Cuesta, M. Díaz-Somoano, M.A. López-Antón, M.R. MartínezTarazona, Oxidised mercury determination from combustion gases using an ionic exchanger, Fuel 122 (2014) 218-222.

[33] R. Terzano, A. Santoro, M. Spagnuolo, B. Vekemans, L. Medici, K. Janssens, J. Gottlicher, M.A. Denecke, S. Mangold, P. Ruggiero, Solving mercury (Hg) speciation in soil samples by synchrotron X-ray microspectroscopic techniques, Environ. Pollut. 158 (2010) 2702-2709.

[34] Y.E. Yudovich, M.P. Ketris, Mercury in coal: a review Part 1. Geochemistry, Int. J. Coal Geol. 62 (2005) 107-134.

[35] L.Y. Kizil'shtein, A.G. Peretyat'ko, G.I. Gofen, Concentration of impurity elements in coals from aspects of the concept of hard and soft acids and bases, Khim. Tverd. Topl. (Chem. Solid Fuels) 23(2) (1989) 132-138.

[36] M. Rumayor, M. Díaz-Somoano, M.A. López-Antón, M.R. Martínez-Tarazona, Application of thermal desorption for the identification of mercury species in solids derived from coal utilization, Chemosphere 119 (2015) 459-465.

[37] N. Fernández-Miranda, M.A. López-Antón, M. Díaz-Somoano, M.R. MartínezTarazona, Effect of oxy-combustion flue gas on mercury oxidation, Environ. Sci. Technol. 48 (2014) 7164-7170.

[38] E.A. Morris, D.W. Kirk, C.Q. Jia, Roles of sulphuric acid in elemental mercury removal by activated carbon and sulphur-impregnated activated carbon, Environ. Sci. Technol. 46 (2012) 7905-7912. 
Table 1. Composition of the combustion and oxy-combustion atmospheres studied

\begin{tabular}{lcc}
\hline Compounds & Combustion & $\begin{array}{c}\text { Oxy- } \\
\text { combustion }\end{array}$ \\
\hline $\mathrm{CO}_{2}(\%)$ & 16 & 64 \\
$\mathrm{~N}_{2}(\%)$ & 74 & 20 \\
$\mathrm{H}_{2} \mathrm{O}(\%)$ & 6 & 12 \\
$\mathrm{O}_{2}(\%)$ & 4 & 4 \\
$\mathrm{SO}_{2}(\mathrm{ppm})$ & 1000 & 1000 \\
$\mathrm{NO}_{(\mathrm{ppm})}$ & 1000 & 1000 \\
$\mathrm{NO}_{2}(\mathrm{ppm})$ & 100 & 100 \\
$\mathrm{HCl}_{(\mathrm{ppm})}$ & 25 & 25 \\
\hline
\end{tabular}

Table 2. Mercury retention capacities of the char samples under combustion and oxycombustion atmospheres

\begin{tabular}{ccc}
\hline Sample & $\begin{array}{c}\text { Combustion } \\
\mathrm{Hg}(\mu \mathrm{g} / \mathrm{g})\end{array}$ & $\begin{array}{c}\text { Oxy-combustion } \\
\mathrm{Hg}(\mu \mathrm{g} / \mathrm{g})\end{array}$ \\
\hline WW & $38 \pm 5$ & $49 \pm 6$ \\
$\mathrm{PW}$ & $185 \pm 10$ & $234 \pm 12$ \\
\hline
\end{tabular}

Table 3. High desorption temperature of pure reference mercury compounds

\begin{tabular}{|c|c|c|}
\hline $\begin{array}{l}\text { Reference Hg } \\
\text { compounds }\end{array}$ & High peak $\mathrm{T}\left({ }^{\circ} \mathrm{C}\right)$ & $\begin{array}{l}\text { Start T- End T } \\
\text { decomposition peak }\left({ }^{\circ} \mathrm{C}\right)\end{array}$ \\
\hline $\mathrm{Hg}_{2} \mathrm{Cl}_{2}^{20}$ & $119 \pm 9$ & $60-250$ \\
\hline $\mathrm{HgCl}_{2}{ }^{20}$ & $138 \pm 4$ & $90-350$ \\
\hline Hg-OM & $220 \pm 5$ & $150-300$ \\
\hline HgS black & $190 \pm 11$ & $150-280$ \\
\hline $\mathrm{HgS}$ red $^{20}$ & $305 \pm 12$ & $210-340$ \\
\hline $\mathrm{HgO}$ red $^{20}$ & $308 \pm 1 ; 471 \pm 5$ & $200-360 ; 370-530$ \\
\hline $\mathrm{HgO}$ yellow ${ }^{20}$ & $284 \pm 7 ; 469 \pm 6$ & $190-380 ; 320-530$ \\
\hline $\mathrm{Hg}_{2} \mathrm{SO}_{4}{ }^{20}$ & $295 \pm 4 ; 514 \pm 4$ & $200-400 ; 410-600$ \\
\hline $\mathrm{HgSO}_{4}{ }^{20}$ & $583 \pm 8$ & $500-600$ \\
\hline $\mathrm{Hg}\left(\mathrm{NO}_{3}\right)_{2} \cdot \mathrm{H}_{2} \mathrm{O}^{20}$ & $215 \pm 4 ; 280 \pm 13 ; 460 \pm 25$ & $150-230 ; 230-375 ; 375-520$ \\
\hline $\mathrm{Hg}_{2}\left(\mathrm{NO}_{3}\right)_{2} \cdot 2 \mathrm{H}_{2} \mathrm{O}^{20}$ & $264 \pm 35 ; 427 \pm 19$ & $100-375 ; 376-500$ \\
\hline
\end{tabular}




\section{Figure captions}

Figure 1. Mercury adsorption curves for WW and PW in coal combustion with air (CO) and oxy-combustion (OX) atmospheres.

Figure 2. Percentages of mercury retained in the char samples (Hgp), oxidized mercury $\left(\mathrm{Hg}^{2+}\right)$ and elemental mercury $\left(\mathrm{Hg}^{0}\right)$ in coal combustion with air and oxy-combustion atmospheres.

Figure 3. Mercury thermal decomposition profiles of mercury standards and postretention char WW in coal combustion with air and oxy-combustion.

Figure 4. Mercury thermal decomposition profiles of the different fractions after sequential extraction for a) WW-OX and b) PW-OX

Figure 5. Mercury thermal decomposition profiles of mercury standards and postretention char PW in coal combustion with air and oxy-combustion.

Figure 6. Distribution of the mercury species in post-retention chars WW-CO, WWOX, PW-CO and PW-OX. 


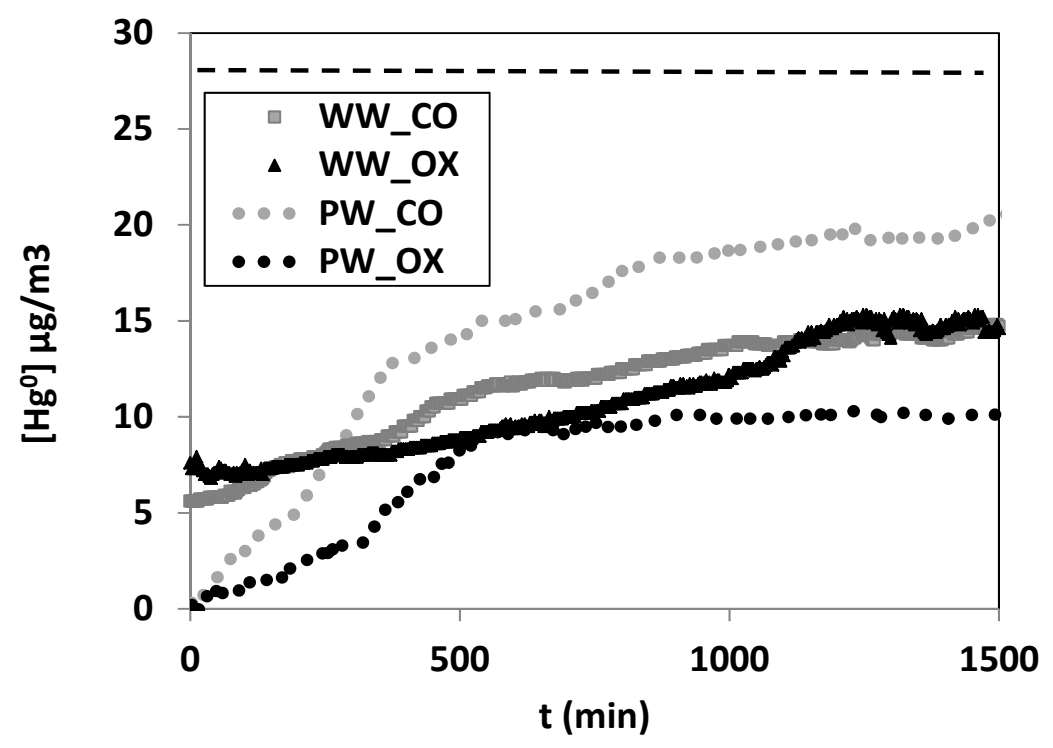

Figure 1

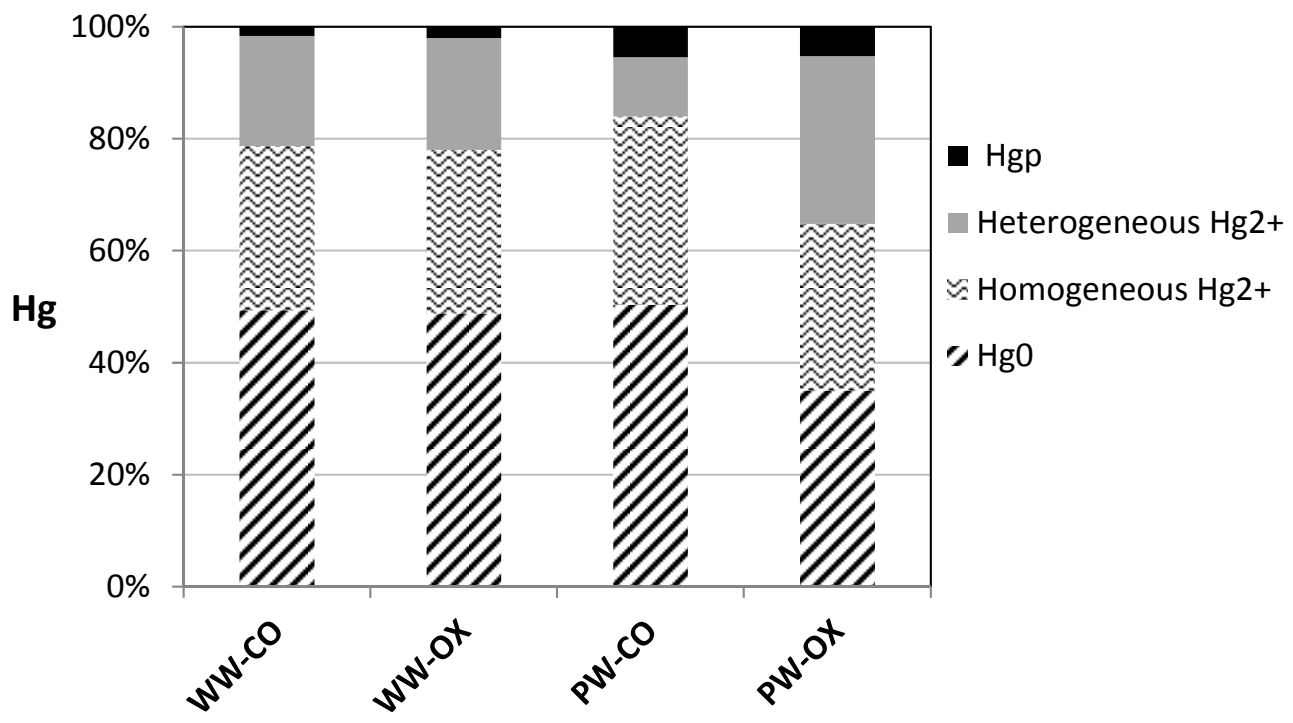

Figure 2 

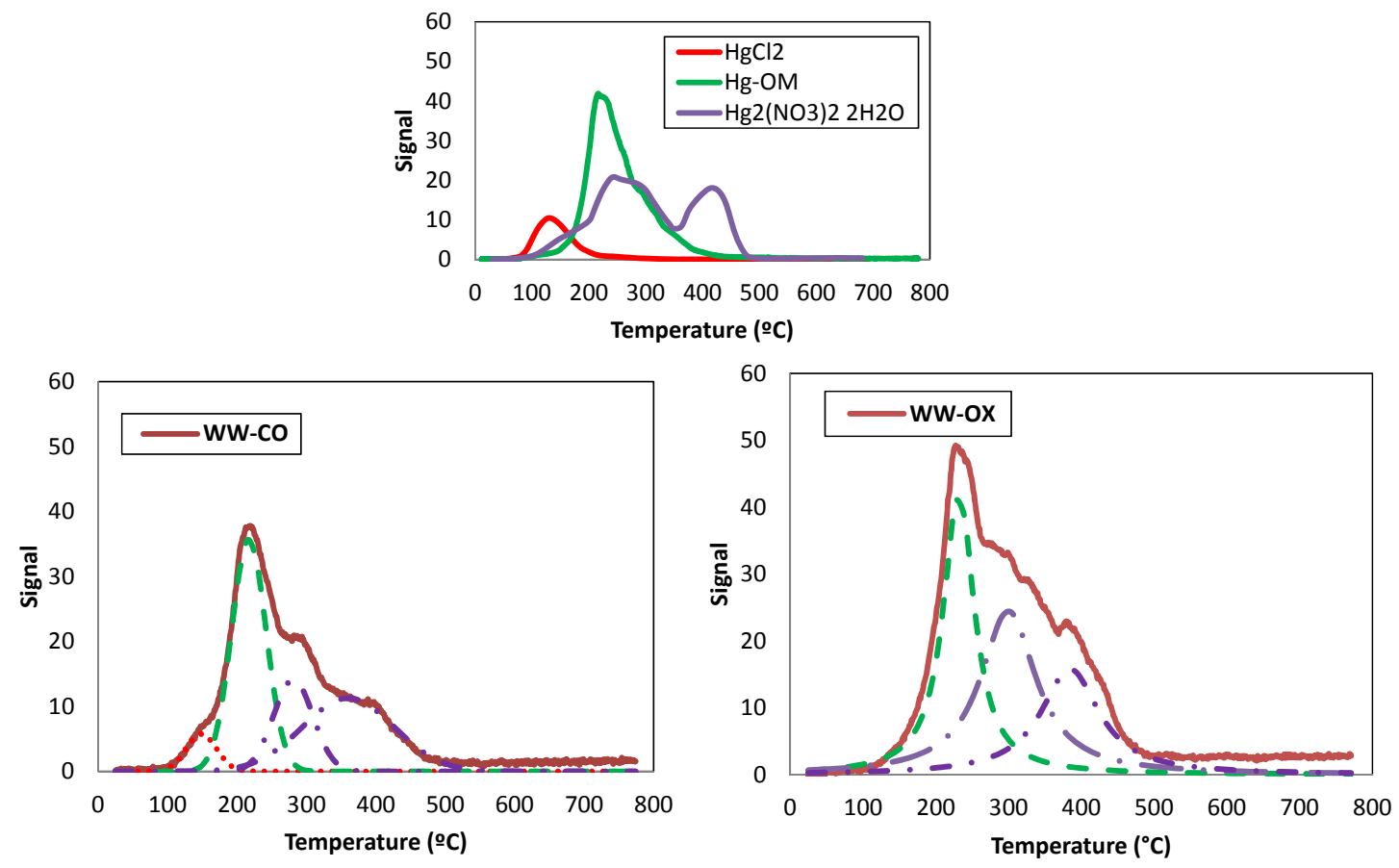

Figure 3
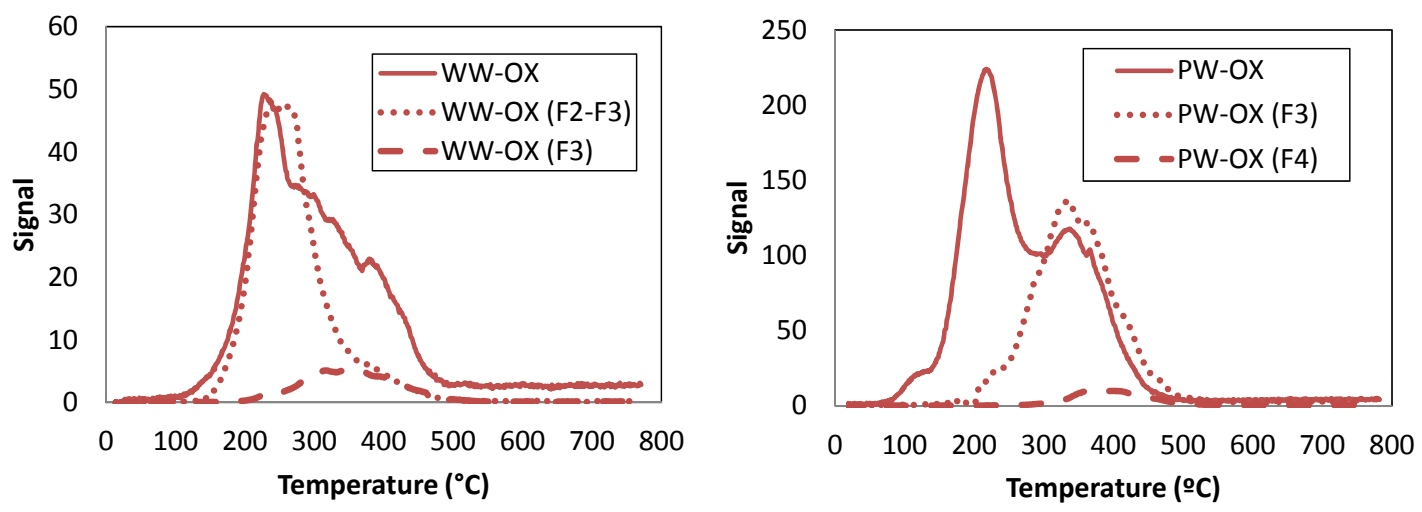

(a)

(b)

Figure 4 

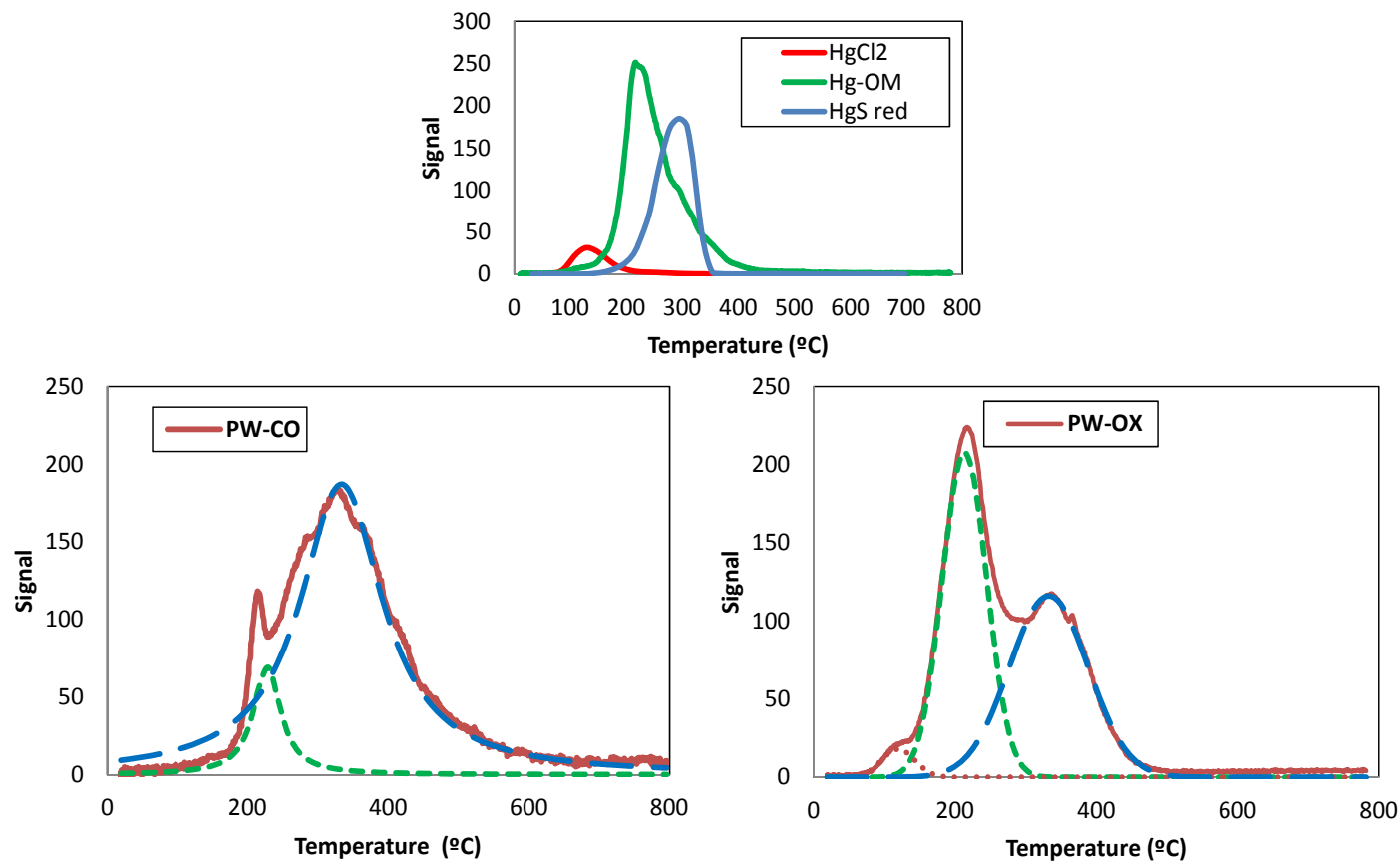

Figure 5

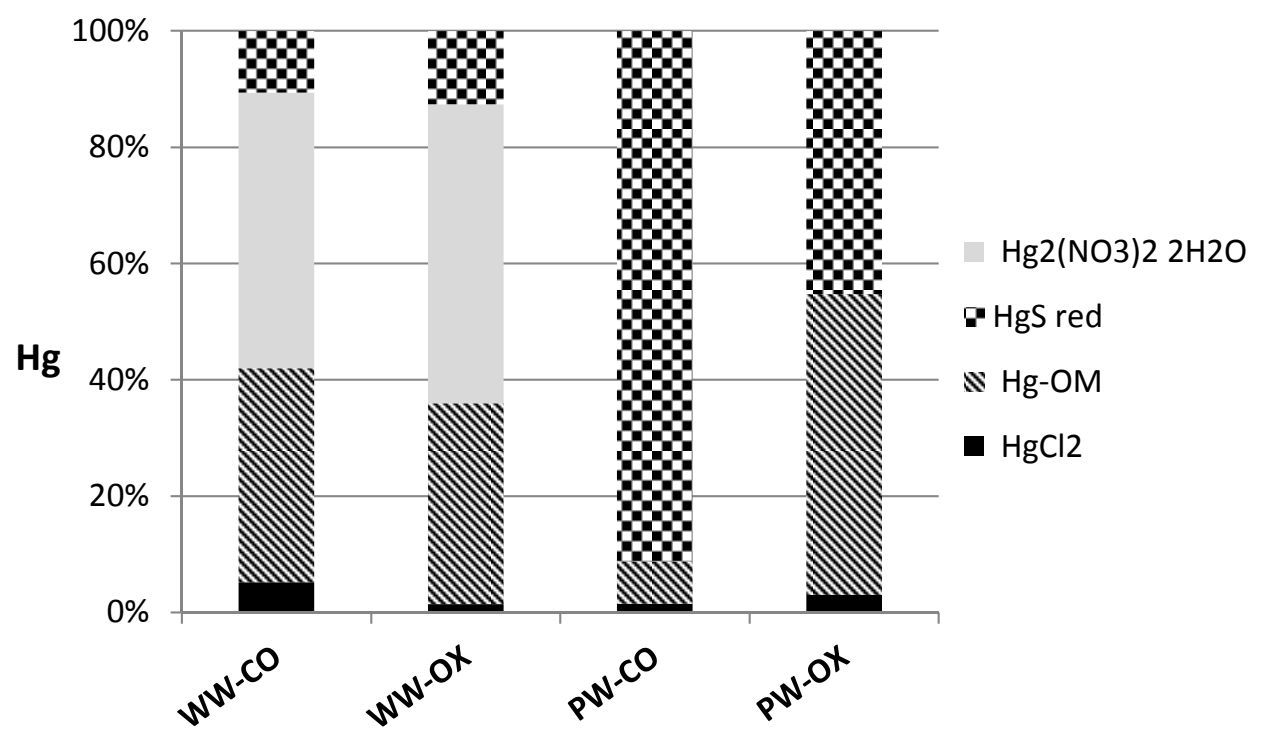

Figure 6 